\title{
Six-month survival of critically ill patients with HIV-related disease and tuberculosis: a retrospective study
}

\author{
Ana Carla Pecego ${ }^{1}$, Rodrigo T. Amancio', Camila Ribeiro', Emersom C. Mesquita', Denise M. Medeiros ${ }^{1}$, \\ José Cerbino', Beatriz Grinsztejn², Fernando A. Bozza ${ }^{1,3}$ and Andre M. Japiassu ${ }^{1 *}$
}

\begin{abstract}
Background: Tuberculosis is one of the leading causes of death from infectious diseases worldwide, mainly after the human immunodeficiency virus (HIV) epidemics. Patient with HIV-related illness are more likely to present with severe TB due to immunosuppression. Very few studies have explored HIV/TB co-infection in critically ill patients. The goal of this study was to analyze factors associated with long-term mortality in critically ill patient with HIV-related disease coinfected with TB.

Methods: We conducted a retrospective study in an infectious disease reference center in Brazil that included all patient with HIV-related illness admitted to the ICU with laboratory-confirmed tuberculosis from March 2007 until June 2012. Clinical and laboratory variables were analyzed based on six-month survival.

Results: Forty-four patients with HIV-related illness with a confirmed diagnosis of tuberculosis were analyzed. The six-month mortality was $52 \%$ (23 patients). The main causes of admission were respiratory failure (41\%), severe sepsis/septic shock (32\%) and coma/torpor (14\%). The median time between HIV diagnosis and ICU admission was 5 (1-60) months, and $41 \%$ of patients received their HIV infection diagnosis $\leq 30$ days before admission. The median CD4 count was 72 (IQR: 23-136) cells $/ \mathrm{mm}^{3}$. The clinical presentation was pulmonary tuberculosis in 22 patients (50 \%) and disseminated TB in 20 patients (45.5\%). No aspect of TB diagnosis or treatment was different between survivors and nonsurvivors. Neurological dysfunction was more prevalent among nonsurvivors (43\% vs. $14 \%, p=0.04)$. The nadir CD4 cell count lower than 50 cells $/ \mathrm{mm}^{3}$ was independently associated with Six-month mortality (hazard ratio 4.58 [1.64-12.74], $p<0.01$ ), while HIV diagnosis less than three months after positive serology was protective (hazard ratio $0.27, \mathrm{Cl} 95 \%[0.10-0.72], p=0.01$ ).
\end{abstract}

Conclusion: The Six-month mortality of HIV critically ill patients with TB coinfection is high and strongly associated with the nadir CD4 cell count less than 50 cels $/ \mathrm{mm}^{3}$.

Keywords: HIV, AIDS, Tuberculosis, Critical care, Patient outcome

\section{Background}

Tuberculosis remains a global health issue and the leading causes of death from infectious diseases worldwide, mainly after the human immunodeficiency virus (HIV) epidemics. The main population affected by $\mathrm{TB}$

\footnotetext{
* Correspondence: andrejapi@gmail.com; andre.japiassu@ipec.fiocruz.br ${ }^{1}$ Intensive Care Clinical Research Laboratory, National Institute of Infectious Diseases (NIID), Av Brasil 4365, Manguinhos, Rio de Janeiro, RJ 21045-900, Brazil

Full list of author information is available at the end of the article
}

mortality is HIV-positive individuals. Throughout 2014, 1.5 million deaths occurred, of which 0.4 million were among seropositive patients [1]. Tuberculosis prophylaxis and treatment is still suboptimal in patients with HIV coinfection in developing countries, even with novel diagnostic tests and antimicrobial agents [1].

Fifteen percent of new TB cases in Brazil are among HIV-infected individuals, which reinforces the recommendation for systematic TB screening for hospitalized patients with HIV-related disease [2-4]. HIV-positive persons that present with advanced immunosuppression 
more frequently present with hematogenous dissemination of the bacillus and multiorgan involvement, and are frequently smear-negative, requiring blood cultures and invasive procedures for diagnosis [5-8].

HIV-TB coinfection accounts for $26.6 \%$ of TB mortality rate [1], and the subgroup of patients that require ICU has an even worse prognosis [4]. Respiratory failure is the most frequent cause of ICU admission of patients with HIV-related illness, and TB is associated with distinct prevalence according to the geographic location where the studies are performed [9-11].

Very few studies have explored HIV/TB coinfection in critically ill patients $[9,12]$. Disseminated presentation of TB, low serum albumin levels, delayed diagnosis and multilobar lung involvement have been identified as markers of poor prognosis $[8,9,13,14]$. Additionally, there is uncertainty about absorption of antituberculosis medications, and drug interactions with antiretroviral therapy are still of concern, mainly when rifampicin and protease inhibitors are prescribed simultaneously $[8,10]$.

The purpose of this study was to identify factors associated with six-month mortality of critically ill patients with HIV-related disease, with confirmed diagnosis of $\mathrm{TB}$ in a major referral center for HIV care in Rio de Janeiro, Brazil.

\section{Methods}

\section{Design and setting}

This is a retrospective study conducted at the ICU of the National Institute of Infectious Disease at Oswaldo Cruz Foundation (FIOCRUZ) in Rio de Janeiro, Brazil. Our institution has provided care to HIV-positive patients since 1986. There are currently over 3.300 HIVpositive adult under active follow-up at Outpatient Clinic. Cohort characteristics have been published elsewhere $[15,16]$. We admit approximately $60-70$ patients with HIV-related disease per year in the ICU.

\section{Definitions, selection of participants and data collection Study procedures}

All files of patients with HIV-related disease admitted to the ICU who received TB treatment from March 2007 to June 2012 were retrospectively reviewed. Only patients with laboratory confirmed tuberculosis were included in this report. The follow-up for six-month survival was checked through consulting electronic data chart of ambulatory and hospital assistance.

Clinical variables related to HIV infection were: cART exposure, time from HIV diagnosis until ICU admission, nadir CD4 cell count, CD4 cell count and HIV viral load recorded at ICU admission or collected in the previous three months prior to hospital admission. Variables for tuberculosis infection were: clinical presentation of tuberculosis (pulmonary or disseminated), clinical specimens that allowed microbiological TB confirmation, anti-tuberculosis drugs prescribed while staying in the ICU, and Mycobacterium tuberculosis resistance diagnosed by culture.

The severity of illness was evaluated using the Simplified Acute Physiological Score (SAPS) II and Sequential Organ Failure Assessment score (SOFA). The SAPS II score assigns points based on age, type of admission (scheduled surgical, unscheduled surgical, or medical), 12 physiological variables, and three underlying disease variable (AIDS, metastatic cancer, and hematologic malignancy); this score expresses the level of acute severity along with age and the presence of these severe comorbidities in the first 24 $\mathrm{h}$ after ICU admission [18]. The score varies from 0 to 163 points, and the higher the SAPS II value, the less is the probability of survival. SOFA score is a semi-quantitative score of six organ dysfunctions, named cardiovascular, respiratory, neurological, hematological, hepatic and renal dysfunctions [19]. It classifies a range of six organ dysfunctions: cardiovascular (hypotension or use of vasopressors); respiratory $(\mathrm{PaO} 2 / \mathrm{FiO} 2$ rate); neurological (Glasgow Coma Scale); renal (serum creatinine level and/or daily diuresis); hepatic (serum bilirubin level); and hematological (platelets level). The score goes from 0 to 24 points, and it can be calculated on a daily basis, in order to evaluate the patient's improvement or worsening. SOFA also gives qualitative information about the Multiple Organ Dysfunction Syndrome (MODS). For ease of interpretation, we also evaluated the initial SOFA score (day 1), since one score higher than 11 points is associated with less than $20 \%$ chance of survival [20]. We also evaluated the use of vasoactive drugs, non-invasive and invasive ventilation support, and hemodialysis. We classified all ICU admission diagnoses as: respiratory insufficiency, severe sepsis or septic shock, coma/torpor and miscellaneous [21].

Demographic and clinical data were categorized according to the survival after six months. The results were displayed as frequency (percentage), median values and interquartile range. If a patient had multiple ICU admissions, only the first was included in this analysis. The ICU team, infectious disease specialist and family members in accordance with local practices shared decisions regarding withholding or withdrawal of treatment.

\section{Case definition}

Tuberculosis was considered confirmed if the bacteriologic case definition was met: direct visualization of acid-fast bacilli (Ziehl-Neelsen stain), ("smear positive"), or a positive culture for Mycobacterium tuberculosis in Lowenstein-Jensen or liquid medium (MIGT). A histopathological result consistent with Tuberculosis in a 
patient with high clinical suspicion was also considered a confirmed case. Patients were excluded if central nervous system (CNS) involvement was highly suggested by CT scan and/or CNS fluid exams, since CNS tuberculosis infection carries a much higher mortality per se and could overscore on CGS [22]. Besides the high mortality rate it could distort the analysis of the group, and therefore it should be analyzed separately.

Combined antiretroviral treatment (cART) exposure before ICU entry meant any cART use regardless of adherence to the treatment. We defined cART as administration of three antiretroviral drugs belonging to at least two classes (i.e., nucleoside reverse-transcriptase inhibitor, non-nucleoside reverse-transcriptase inhibitor, protease inhibitor, integrase inhibitor).

In our population, we had two scenarios of the administration of TB drugs while in the ICU, according to the hemodynamic status. In the case of hemodynamic unstable patients, TB drugs were delivered intravenously; fluoroquinolones and aminoglycosides were the drugs of choice. When the patient was hemodynamically stable, TB drugs could be delivered per enteral or oral route; the combination of Rifampicin (R), Isoniazid (H), Pyrazinamide $(\mathrm{P})$, Ethambutol $(\mathrm{E})$ were the preferred drugs given by oral/enteral route.

Disseminated TB was defined when: thoracic X-ray or $\mathrm{CT}$ scan showed a pattern that indicated dissemination; two non-contiguous sites were involved in accordance with WHO 2013; or Mycobacterium tuberculosis was recovered from the bloodstream [1].

Drug resistance was defined as resistant to $\geq 1$ drug [17], and Multidrug-resistant tuberculosis (MDR) defined as TB caused by strains of Mycobacterium tuberculosis that are resistant to at least isoniazid and rifampicin [23].

\section{Laboratory procedures}

Resistance towards anti-TB drugs was determined by culture methods using liquid media or LowensteinJensen slants.

\section{Statistical analysis}

We analyzed the clinical and laboratory variables according to six-month survival after ICU admission using GraphPad Prism version 6.0 for MAC OS X (GraphPad Software, San Diego, CA, USA) and Epi Info ${ }^{\mathrm{ma}}$ version 7.1 (Centers for Disease Control, Atlanta, GA, USA). The numerical demographic variables were expressed as the median and the interquartile range (IQ 25-75\%). All of the numerical variables were tested for normality using the Kolmogorov-Smirnov test. We compared continuous variables using a $t$-test (parametric distribution) and the Mann-Whitney $U$ test (nonparametric distribution). The categorical variables were compared using the chi-squared test and Fisher's exact test. We categorized two numerical variables, since the dispersion was wide: CD4 cell count (below 50 cells/mm3) and time since HIV diagnosis (recent HIV means less than three months after positive HIV serology). We performed the survival analysis with Cox proportional hazards to analyze factors associated with six-month survival, selecting variables with $\mathrm{p}$ values lower than 0.2 in the univariate comparison. A Kaplan-Meier curve was constructed based on independent factors associated with six-month survival.

\section{Results}

Clinical characteristics of patient with HIV-related illness with tuberculosis in the ICU

During the five years study period, 267 HIV/AIDS patients were admitted to the ICU and 63 received tuberculostatic treatment. Among these, 49 had laboratory-confirmed tuberculosis; four patients were excluded because of confirmed TB CNS involvement and one patient was transferred to another hospital. A total of 44 patients with HIV-related disease with confirmed TB were included in the study. All patients were followed up to six months after ICU discharge. The ICU mortality was $48 \%$ (21 patients), one patient died after being transferred to the hospital ward and one patient died within the following six months after ICU discharge (Fig. 1).

The median age was 34 (IQR: 19-44.5) years, with a predominance of males $(70 \%)$ (Table 1$)$. The main reasons for ICU admission were respiratory failure (41\%), severe sepsis/septic shock (32\%), coma/torpor (14\%), and miscellaneous (13\%). The SAPS II score was 47 (IQR: 37-55) points, and the SOFA score on day 1 of the ICU stay was 4 (IQR: $1-8)$ points. Mechanical ventilation was needed in $63 \%$ of patients.

The main differences between survivors and nonsurvivors for six-month mortality were: nadir CD4 cell count, median time length between HIV-infection diagnoses and ICU admission, SOFA score, and neurological dysfunction. Twenty-one (45\%) patients had a recent HIV diagnosis (within three months before hospital admission). The most recent median CD4 cell count was 36 [IQR: 15-80] in nonsurvivors vs. 100 [IQR: 58-243] cells $/ \mathrm{mm}^{3}$ in survivors $(p=0.01)$; with a median time between CD4 cell count and ICU admission - 0.5 months (IQR: -2.25-0).

Twenty-five $(57 \%)$ patients were previously exposed to cART, and only 4 (9\%) presented with undetectable viral load (less than 50 copies $/ \mathrm{ml}$ ). Combined ART was used in 17 (39\%) patients while in the ICU, with no statistical difference in both, hospital mortality (52\% vs $29 \%, p=0.23$ ) and in six months survival (48 \% vs $30 \%$ $p=0.35$ ). There was no statiscally difference in six- 


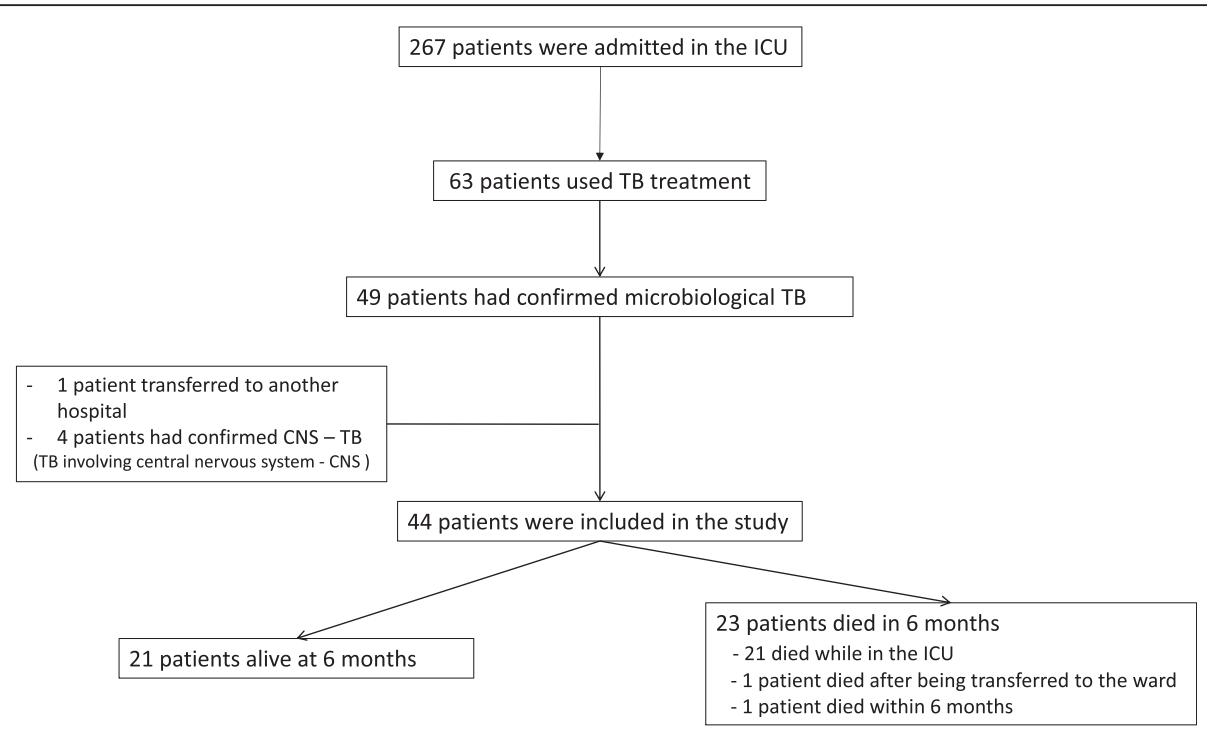

Fig. 1 Flow diagram for study inclusion

month mortality between survivors and nonsurvivors using cART while in the ICU ( $48 \%$ vs $30 \%, p=0.35$ ). There was no difference in six-month mortality between survivors and nonsurvivors using cART during the first week of ICU stay ( $38 \%$ vs $17 \%, p=0.09$ ), or during the 2nd week ( $33 \%$ vs $35 \%, p=0.78$ ). None of the patients presented IRIS nor revealed an unmasked infection while taking CART in the ICU.

\section{Tuberculosis diagnosis and treatment}

No aspect of TB diagnosis or treatment was different in survivors or nonsurvivors. Twenty-two pulmonary TB cases $(50 \%)$ and 22 disseminated (50\%) TB cases were equally distributed between the 2 groups (Table 1). Tuberculosis was diagnosed from respiratory samples in the majority of cases. Thirty-two $(73 \%)$ patients were diagnosed through direct visualization of the bacillus using the Ziehl-Neelsen technique (27 in the sputum and 5 in the bronchoalveolar lavage); the diagnosis was only made through culture of respiratory specimens in 5 (11\%) patients. Bacteremia due to Mycobacterium tuberculosis was found in $6(14 \%)$ patients. Eleven (25\%) patients required invasive procedures for TB diagnosis, such as organ biopsy. The main TB regimens prescribed were per oral or enteral routes in 16 patients, while the addition of intravenous drugs (mostly aminoglycosides and quinolones) was chosen in 28 patients. The combination of oral/enteral drugs was composed by HRZ ( $n=$ $8)$ or HRZE $(n=8)$ schemes. Intravenous fluoroquinolones and aminoglycosides were prescribed in 27 (61\%) and $22(50 \%)$ patients, respectively.

We identified resistance to $M$. tuberculosis in specimen cultures from $5(11 \%)$ patients: resistance to streptomycin $(n=4)$, isoniazid $(n=2)$, and rifampin $(n=1)$. From these five patients, only one patient with isolated resistance to streptomycin survived; the other four patients with a pattern of resistance died. None of 44 patients included had multidrug resistant Mycobacterium tuberculosis strains.

\section{Organ dysfunctions}

Although not statistically significant on day 1 of ICU admission, the SOFA score was higher among non-survivors $(p=0.08)$ (Table 1). For this reason, we decided to determine if any of the six organ dysfunctions could be associated with six-month survival. Only neurological dysfunction was statistically different: 10 (43\%) nonsurvivors vs. 3 (14 \%) survivors presented with neurological dysfunction, $p=0.04$. Neurological dysfunction was described as GCS of 13-14 points (somnolence) in 9 patients, and GCS of 8-10 points (torpor) in four patients. One patient had seizures, two patients had gait disturbances and one patient had paresthesia. None had neck stiffness, delirium [24] or intracranial hypertension. Of the four patients with a GCS of less than 12 points, all had head CT scans and three had liquor studies: three patients were diagnosed with neurotoxoplasmosis and one patient had normal head CT scan.

\section{Six-month outcome}

The nadir CD4 cell counts lower than 50 cells $/ \mathrm{mm}^{3}$ was independently associated with six-month mortality (hazard ratio 4.58 [1.64-12.74], $p=0.004$ ), while recent HIV diagnosis (less than three months after positive serology) was protective (hazard ratio 0.27 , CI $95 \%$ [0.10-0.72], $p=0.01$ ) (Table 2). We observed a lower six-month 
Table 1 Characteristics critically ill HIV patients coinfected with TB (laboratory-confirmed) diagnosis, including the characteristics of Tuberculosis (TB) presentation and treatment and the prevalence of organ dysfunctions at ICU admission $(N=44)$

\begin{tabular}{|c|c|c|c|c|}
\hline & HIV/AIDS and Tuberculosis $(N=44)$ & Survivors $(N=21)$ & Non-survivors $(N=23)$ & $p$ value \\
\hline Age (years) & $34(19.25-44.5)$ & $32(27-42.5)$ & $36(30-46)$ & 0.15 \\
\hline Gender (male) & $31(70 \%)$ & $14(67 \%)$ & $17(74 \%)$ & 0.74 \\
\hline Nadir $C D 4^{a}$ & $54(17-96)$ & $73(30-177)$ & $23(14-84)$ & 0.04 \\
\hline Viral load $\left(\times 10^{3}\right.$ copies $/ \mathrm{mm}^{3) b}$ & $113,637(2,995-365,663)$ & $35,149(212.3-300,184)$ & $169,133(35,405-419,382)$ & 0.13 \\
\hline Length of time since HIV diagnosis (months) & $5(1-60)$ & $1(1-16)$ & $28(1-72)$ & 0.03 \\
\hline CART use while in the ICU & $17(38.6 \%)$ & $10(48 \%)$ & $7(30 \%)$ & 0.35 \\
\hline Mechanical ventilation use on ICU day 1 & $21(48 \%)$ & $8(42 \%)$ & $13(52 \%)$ & 0.56 \\
\hline Vasoactive drug use on ICU day 1 & $12(26 \%)$ & $5(24 \%)$ & $7(27 \%)$ & 0.99 \\
\hline SAPS II score (points) & $47(37-55)$ & $48(37-57)$ & $46(38-54)$ & 0.27 \\
\hline SOFA score on day 1 (points) & $4(1-8)$ & $1(0-7)$ & $5(2-8)$ & 0.08 \\
\hline Isolated TB pulmonary presentation & $22(50 \%)$ & $10(48 \%)$ & $12(52 \%)$ & 1.00 \\
\hline Disseminated TB presentation & $22(50 \%)$ & $11(52 \%)$ & $11(48 \%)$ & 1.00 \\
\hline TB treatment before ICU admission & $25(57 \%)$ & $11(52 \%)$ & $14(61 \%)$ & 0.76 \\
\hline \multicolumn{5}{|l|}{ TB treatment } \\
\hline - only by enteral drugs & $16(36 \%)$ & $10(48 \%)$ & $6(26 \%)$ & 0.21 \\
\hline - adding intravenous drugs & $28(64 \%)$ & $11(52 \%)$ & 17 (74 \%) & \\
\hline TB treatment: $\Delta$ ICU admission & $0(-5-+21)$ & $-5(-23-+2)$ & $-5(-21-0)$ & 0.09 \\
\hline TB treatment before ICU & $25(57 \%)$ & $11(52.4 \%)$ & $14(61 \%)$ & 0.76 \\
\hline \multicolumn{5}{|l|}{ Organ Dysfunctions } \\
\hline Cardiovascular & $18(41 \%)$ & 7 (33.3 \%) & $11(48 \%)$ & 0.37 \\
\hline Respiratory & $15(34 \%)$ & $5(24 \%)$ & $10(43 \%)$ & 0.21 \\
\hline Renal & $14(32 \%)$ & $5(24 \%)$ & $9(39 \%)$ & 0.34 \\
\hline Neurological & $13(29 \%)$ & $3(14 \%)$ & $10(43 \%)$ & 0.04 \\
\hline Hepatic & $9(20 \%)$ & $5(24 \%)$ & $4(17 \%)$ & 0.71 \\
\hline Hematological & $9(20 \%)$ & $3(14 \%)$ & $6(26 \%)$ & 0.46 \\
\hline
\end{tabular}

Comparison between survivors and nonsurvivors for six-month survival. Results were expressed as the median and the interquartile interval

adata available for 39 patients

bdata available for 35 patients

$\Delta$ :time from starting TB treatment and beeing admitted to ICU. Negative (-) mean prior to ICU admission and positive (+) means after ICU admission

survival in patients with nadir CD4 cell counts lower than 50 cells $/ \mathrm{mm}^{3}(\log \operatorname{rank}$ test $p=0.006)$ (Fig. 2).

\section{Discussion}

The coinfection HIV-TB presented a high long-term mortality in our cohort. The nadir CD4 cell count was

Table 2 Cox proportional analysis and adjusted hazard ratio for six-month mortality $(95 \% \mathrm{Cl})$ of critically ill patients with HIVrelated disease with tuberculosis $(N=44)$

\begin{tabular}{|c|c|c|}
\hline Variable & $\begin{array}{l}\text { Adjusted Hazard ratio } \\
\text { for six-month mortality }\end{array}$ & $p$ value \\
\hline $\begin{array}{l}\text { Nadir CD4 cell count less } \\
\text { than } 50 \text { cells } / \mathrm{mm}^{3}\end{array}$ & $4.58[1.64-12.74]$ & 0.004 \\
\hline Age at inclusion & $1.03[0.99-1.08]$ & 0.07 \\
\hline SOFA score at ICU admisson & $1.09[0.97-1.22]$ & 0.13 \\
\hline Recent HIV diagnosis at admission ${ }^{a}$ & $0.27[0.10-0.72]$ & 0.009 \\
\hline
\end{tabular}

the independent marker for six-month mortality, while a HIV diagnosis up to three months before hospital admission was protective among these severely ill HIV-TB patients. No aspect of tuberculosis presentation or treatment influenced the outcome. Among the organ dysfunctions, neurological dysfunction was more frequent in nonsurvivors, even after the exclusion of those patients with primary TB CNS involvement.

\section{HIV infection and critical illness}

Since the beginning of the HIV epidemic, respiratory failure has been the main reason for ICU admission with the spectrum of etiological agents changing according to the geographic region and cART access [25-28]. Influenza, pneumococcal vaccination and TB background prevalence also influence the main causes of respiratory disease in this population [29-32]. Tuberculosis is highly prevalent in Brazil, mainly in Rio de Janeiro, and the 


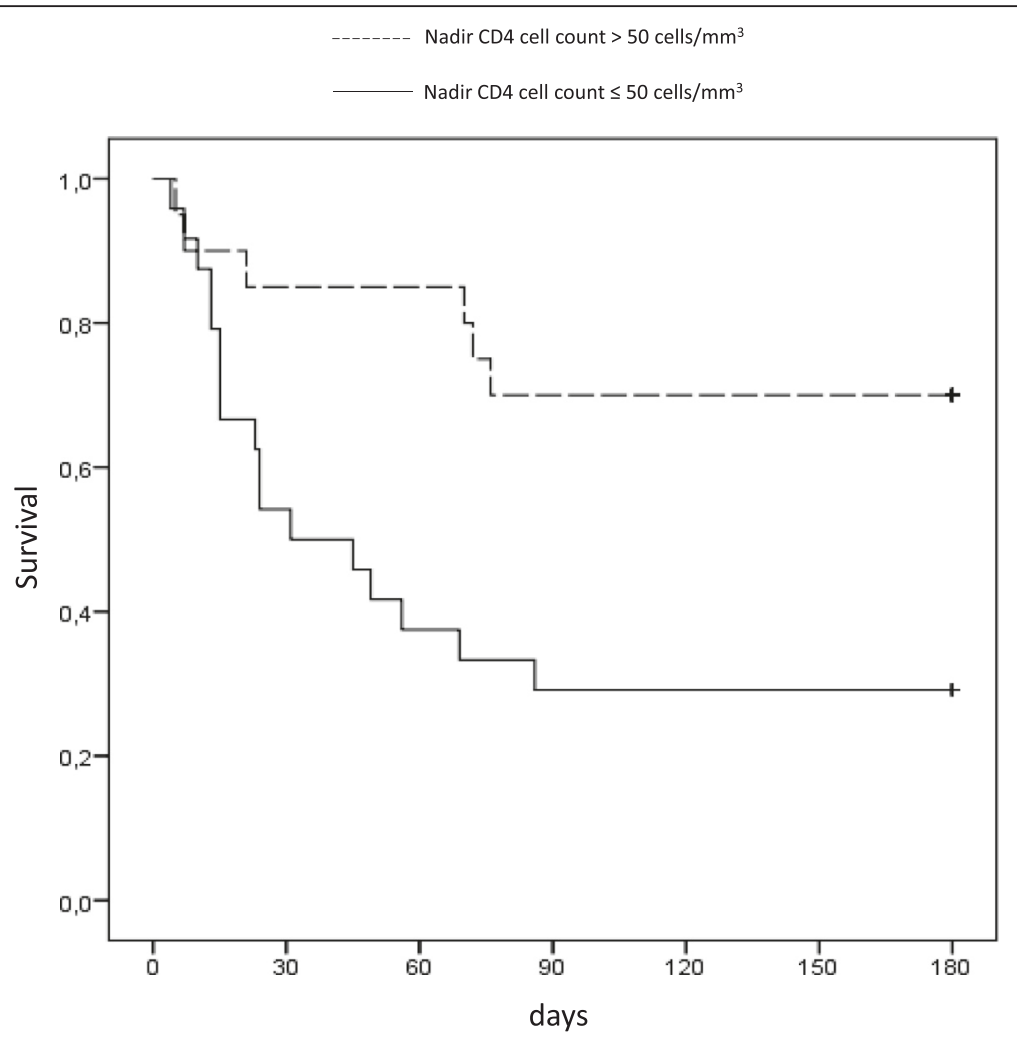

Fig. 2 Kaplan-Meier plot of six-month survival in critically ill patients with HIV-related disease and tuberculosis, based on nadir CD4 cell count less than 50 cells $/ \mathrm{mm}^{3}$. Log-rank test $p=0.006$

HIV infection epidemic has made TB a common cause of opportunistic infections responsible for AIDS diagnosis in our population $[2,33]$. Rio de Janeiro has one of the worst scenarios in regards to the Tuberculosis epidemic in Brazil. In 2012, 10,649 new tuberculosis cases were diagnosed in Rio de Janeiro State, with an incidence rate of $65.6 / 100.000$ person-years, a rate much higher than the overall country incidence rate of 35.8/ 100.000 person-years. The mortality rate among TB patients from Rio de Janeiro is the second highest in the entire country, reaching 5.1/100.000 person-years.

Respiratory failure is the main reason for ICU admission among pulmonary HIV-TB patients [8-10], as we described in our population, even though $45 \%$ of patients present with disseminated tuberculosis. Isolated extrapulmonary disease was uncommon (5\%).

Severe immunosuppression caused by HIV infection is a known risk factor for tuberculosis [7]. As immunosuppression evolves, the TB disease spectrum changes from its classic pulmonary presentation of unilateral upper lobe infiltrate to a broad range of nonspecific signs and symptoms related to hematogenic spread of the bacillus. The myriad of presentations of $\mathrm{TB}$ in the population with HIV-related disease is associated with challenges in establishing the diagnosis and higher mortality [33]. Our high proportion of disseminated TB (45\%) is due to the advanced immunodeficiency status of our population, with median CD4 cell counts of 72 cells $/ \mathrm{mm}^{3}$, which were lower than previously reported (109 and 112 CD4 cells $\left./ \mathrm{mm}^{3}\right)[28,29]$. CD4 cell count is thought to be an unreliable predictor of ICU mortality, according to Morris and colleagues, when compared to other known risk factors, such as mechanical ventilation, low serum albumin and APACHE II score [11, 34-37]. However, others authors believe that CD4 cell count does have a correlation with a poorer prognosis [25, 38-40]. Low CD4 counts $\left(<200\right.$ cells $\left./ \mathrm{mm}^{3}\right)$ have been associated with ICU mortality in HIV patients with TB [41]. In the present study, we found that patients with higher nadir CD4 cell counts were more likely to be alive six months after hospital discharge. These data are supported by the idea that CD4 cell counts at ICU admission are a better marker of long-term prognosis [42]. We preferred nadir than recent $\mathrm{CD} 4$ cell count because opportunistic infections and concomitant acute infections can lower the CD4 cell count [45]. Alongside with the low nadir CD4 cell count, we wanted to emphasize that we also observed a low median CD4 count close to ICU admission meaning that our population represents a profoundly immunocompromised population. Also, nadir CD4 cell count it is better marker of prognosis and disease evolution in HIV infected population [43, 44]. We also found 
that recent HIV diagnosis was associated with protective effect for long term survival. This variable should be evaluated with caution: there is not an accurate correlation of the moment of first HIV positive serology and the time since HIV infection began. Some patients are admitted with recent HIV diagnosis and very low nadir CD4 count, although they were previously less exposed to bacterial and multilple oportunistic infections and to the HIV infection per se, than their peers with long known HIV diagnosis and non-adherence to cART. This state of chronic immunosuppression by HIV and opportunistic infections may have contributed to a lower survival rate in this population, as shown previously in a heterogeneous group of studies with and without cART influence [11, 30, 58].

As show earlier from our institution's cohort, the HIV diagnosis frequently occurs during an advanced immunodeficiency state, which can be associated with a high prevalence of tuberculosis [46]. Earlier diagnosis is fundamental to diminish the complications of the advanced immunodeficiency.

Delivering cART in critically ill patients is still controversial. The limited availability of intravenous medications, potential drug-to-drug interactions, erratic gastrointestinal absorption and the risk of unmasking infections and IRIS are considerations in the setting of critically ill patient with HIV-related disease [37, 38, 53]. The administration of cART did not influence short- or long-term survival in our study, but we cannot conclude that CART administration in the ICU is not beneficial since it was not possible to assure adherence of all patients taking cART after hospital discharge, which is fundamental to the success of the treatment. In the present study, we did not find Immune Reconstitution Inflammatory Syndrome (IRIS) criteria in any case, nor did we find any severe adverse reactions attributed to cART.

\section{Characteristics of tuberculosis infection}

The recovery of $M$. tuberculosis from blood cultures is suggestive of disseminated TB, and we found bacteremia in $14 \%$ of patients. This is a common etiologic agent of sepsis in population with HIV-related disease, as observed in two published works by our group and other groups [11, 29, 43-49]. Research suggests that patients with disseminated and extra-pulmonary forms of tuberculosis may represent a special group that may be associated with worse outcomes, including greater risk for the tuberculosis immune reconstitution inflammatory syndrome [50]. TB treatment in the acute phase of critically ill patients can often be suboptimal $[51,52]$ because first line drugs are only available in oral formulations. One could suppose that intravenous treatment could improve outcomes (fluoroquinolones and aminoglycosides). However, in this case series, we found a high proportion of critically ill patients using rifampin, isoniazid and pyrazinamide, and half of our patients received intravenous quinolones and/or aminoglycosides as the first treatment for TB with no difference in sixmonth survival.

\section{Risk factors for long-term mortality}

The six-month mortality observed in our study was high (52\%), but lower than reported from other retrospective studies involving patients with TB admitted to the ICU (hospital mortality 22-67 \%) [10, 41, 54]. Another interesting point was that the disseminated form of TB had a similar mortality to pulmonary presentation ( $45 \%$ and $50 \%$, respectively). This may be different from another study, which enrolled 46 HIV-TB patients, including suspected cases of $\mathrm{TB}$, although we included only confirmed cases [10]. Finally, improvements in the care of critically ill patients, such as implementation of protective ventilator strategies with low tidal volume, conservative fluid strategy for Acute Respiratory Distress Syndrome (ARDS), and early sepsis goals, have added benefits and have recently had an impact on lower mortality rates $[28,34,55]$.

This study highlights neurological dysfunction as being an important marker for mortality among critically ill HIVTB patients. These findings cannot be attributed to encephalitis or meningitis that is primarily caused by TB. We excluded CNS involvement (encephalitis or meningitis), which carries a poorer prognosis [56, 57]. All patients with $\mathrm{GCS} \leq 11$ had a lumbar puncture performed. The majority of our neurological findings were mild; most of them were classified as torpor. As shown previously, low GCS at admission can be a reliable predictor of ICU mortality $[35,58]$. In our analysis, neither SOFA nor SAPS II was able to predict survival. Another two studies have found correlation between higher SAPS II and ICU mortality [35, 51]. Zahar et al. investigated laboratory-confirmed tuberculosis cases, $38 \%$ were patients with HIV-related, all with respiratory failure, and the majority with a pulmonary presentation; higher SAPS II (approximately 45 points) and the presence of more than one organ failure were significantly associated with mortality [51]. Meybeck et al. showed that SAPS II was significantly higher in nonsurvivors (approximately 55 points) with an odds ratio of 1.05 per point [35]. The SAPS II score was similar between sixmonth survivors and nonsurvivors in our study, while SOFA scores on the day of ICU admission trended towards being higher in nonsurvivors $(p=0.08)$.

\section{Limitations of the study}

We realize that our study has several limitations. First, it is a retrospective single-center study conducted in a specialized infectious disease hospital, and these findings cannot be extrapolated to other centers. The fact that we did not find IRIS in our population may due to the 
retrospective nature of the study since we did not have clear definitions since the beginning of our cohort. The limited number of patients (44 patients) is another limitation of our study since we are exploring a very specific population. However, the results here presented should increase awareness to important factors that may contribute to a better management of HIV-TB patients in the ICU, and for pointing to future researches. Regarding the neurological findings, due to its retrospective nature, we were not able to detect broader neurological involvement, such as delirium and intracranial hypertension [58]. Delirium screening using the Confusion Assessment Method (CAM-ICU) assessment is not a routine practice at our institution [24].

\section{Conclusions}

The six-month mortality of HIV critically ill patients with TB coinfection is high and strongly associated with the nadir CD4 cell count less than 50 cels $/ \mathrm{mm}^{3}$. Neurological dysfunction may be associated with poor survival, even without primary CNS involvement.

\begin{abstract}
Abbreviations
APACHE, acute physiological assessment and chronic health evaluation; ARDS, acute respiratory distress syndrome; CAM, confusion assessment method; CART, combined antirretroviral therapy; CGS, coma glasgow scale; CNS, central nervous system; CT, computed tomography; HIV, human immunideficiency virus; ICU, intesive care unit; IRIS, immune reconstitution inflammatory syndrome; MDR, multidrug-resistant; MODS, multiple organ dysfunction syndrome; SAPS, simplified acute physiological score; SOFA, sequenctial organ failure assessment score; TB, tuberculosis
\end{abstract}

\section{Acknowledgements}

We express our thanks to the staff members from Intensive Care Unit (ICU) of the National Institute of Infectious Disease (INI) at Oswaldo Cruz Foundation (FIOCRUZ) for their assistance in this study.

\section{Funding}

- National Council of Technological and Scientific Development (CNPq).

FAB is scholar from CNPq.

- Research Funding Agency of the State of Rio de Janeiro (FAPERJ).

\section{Authors' contributions}

$A C P, R T A, F A B$ and $A M J$ conceived the study and proposed its design; ACP, RTA, ECM and CR performed the data collection and summarized the descriptive results; AMJ and RTA performed the data analysis; ACP, AMJ and RTA wrote the manuscript; $B G, J C, D M$ and FAB helped to draft the final manuscript by making a critical revision. All authors read and approved the final manuscript.

\section{Competing interests}

The authors declare that they have no competing interests.

\section{Ethics approval and consent to participate}

This study was conducted in accordance with the Declaration of Helsinki and local ethical legislation. The Institutional Review Board (Research Ethics Committee from National Institute of Infectious Diseases (FIOCRUZ), at Rio de Janeiro, Brazil, approved the study protocol, and informed consent was waived.

\section{Author details}

IIntensive Care Clinical Research Laboratory, National Institute of Infectious Diseases (NIID), Av Brasil 4365, Manguinhos, Rio de Janeiro, RJ 21045-900, Brazil. ${ }^{2}$ STD/AIDS Clinical Research Laboratory, National Institute of Infectious Diseases (NIID), Av Brasil 4365, Manguinhos, Rio de Janeiro, RJ 21045-900,
Brazil. ${ }^{3}$ Instituto D'Or de Pesquisa e Ensino, Rua Diniz Cordeiro, $n^{\circ}$ 30, Botafogo, Rio de Janeiro, RJ 22281-100, Brazil.

Received: 8 January 2015 Accepted: 8 June 2016

Published online: 10 June 2016

\section{References}

1. WHO | Global tuberculosis report 2014 [Internet]. WHO. [cited 2014]. Available from: www.who.int/tb/publications/global_report/gtbr14_main_text.pdf. Accessed 15 Nov 2015

2. Grinsztejn B, Veloso VG, Friedman RK, Moreira Rl, Luz PM, Campos DP, et al. Early mortality and cause of deaths in patients using HAART in Brazil and the United States. AIDS. 2009:23(16):2107-14.

3. Manual de Recomendações para controle da tuberculose no Brasil. Série A. Normas e Manuais Tácnicos. Ministério da Saúde. 2011.

4. Silva DR, Gazzana MB, de TR DP. Severe tuberculosis requiring ICU admission. J Bras Pneumol. 2012;38(3):386-94.

5. Pawlowski A, Jansson M, Sköld M, Rottenberg ME, Källenius G. Tuberculosis and HIV Co-Infection. PLoS Pathog. 2012;8(2):e1002464. Hobman TC, editor.

6. Zumla A, Raviglione M, Hafner R. Fordham von Reyn C. Tuberc N Engl J Med. 2013;368(8):745-55

7. Gary J, Cohn D. Tuberculosis and HIV Coinfection. Semin Respir Crit Care Med. 2013;34(01):032-43.

8. Hagan G, Nathani N. Clinical review: Tuberculosis on the intensive care unit. Crit Care. 2013;17(5):240

9. Erbes R. Characteristics and outcome of patients with active pulmonary tuberculosis requiring intensive care. Eur Respir J. 2006;27(6):1223-8.

10. Silva DR, Menegotto DM, Schulz LF, Gazzana MB, Dalcin PT. Mortality among patients with tuberculosis requiring intensive care: a retrospective cohort study. BMC Infect Dis. 2010;10(1):54.

11. Japiassú AM, Amâncio RT, Mesquita EC, Medeiros DM, Bernal HB, Nunes EP, et al. Sepsis is a major determinant of outcome in critically ill HIV/AIDS patients. Crit Care. 2010;14(4):R152.

12. Amâncio FF, Lambertucci JR, Cota GF, Antunes CM. Predictors of the shortand long-term survival of HIV-infected patients admitted to a Brazilian intensive care unit. Int J STD AIDS. 2012;23:692-7.

13. Abdullah AA, Yaseen MA, Hamdan A-J, Ashwaq O, Othman Al H, Ziad M. Clinical presentation and outcome of patients diagnosed with active pulmonary tuberculosis in a large critical care unit. Crit Care Shock. 2011;14:1-6.

14. Sarkar P, Rasheed HF. Clinical review: Respiratory failure in HIV/AIDS patients - a changing picture. Crit Care. 2013;17(3):228.

15. Cardoso SW, Luz PM, Velasque L, Torres TS, Tavares IC, Ribeiro SR, Moreira RI Veloso VG, Moore RD, Grinsztejn B. Outcomes of second-line combination antiretroviral therapy for HIV-infected patients: a cohort study from Rio de Janeiro, Brazil. BMC Infect Dis. 2014;14:699. doi:10.1186/s12879-014-0699-5.

16. Coelho L, Cardoso SW, Amancio RT, Moreira Rl, Campos DP, Veloso VG, Grinsztejn B, Luz PM. Trends in AIDS-defining opportunistic illnesses incidence over 25 years in Rio de Janeiro, Brazil. PLoS One. 2014;9(6):e98666. doi:10.1371/journal.pone.0098666.

17. Conde MB, Melo FAF, Marques AMC, Cardoso NC, Pinheiro VGF, Dalcin PTR, et al. III Brazilian Thoracic Association Guidelines on Tuberculosis. J Bras Pneumol. 2009;35(10):1018-48.

18. Vincent JL, Moreno R, Takala J, Willatts S, De Mendonça A, Bruining H, et al. The SOFA (Sepsis-related Organ Failure Assessment) score to describe organ dysfunction/failure. Intensive Care Med. 1996;22(7):707-10.

19. Le Gall JR, Lemeshow S, Saulnier F. A new Simplified Acute Physiology Score (SAPS II) based on a European/North American multicenter study. JAMA. 1993;270(24):2957-63.

20. Moreno R, Vincent UL, Matos R, Mendonça A, Cantraine F, Thijs L, Takala J, Sprung $\mathrm{C}$, Antonelli M, Bruining $\mathrm{H}$, Willatts $\mathrm{S}$. The use of maximum SOFA score to quantify organ dysfunction/failure in intensive care. Results of a prospective, multicentre study. Working Group on Sepsis related Problems of the ESICM. Intensive Care Med. 1999;25(7):686-96.

21. Huang L, Quartin A, Jones D, Havlir DV. Intensive care of patients with HIV infection. N Engl J Med. 2006;355(2):173-81.

22. Torok ME, Chau TTH, Mai PP, Phong ND, Dung NT, Chuong LV, et al. Clinical and Micribiological features of HIV-Associated Atuberculous Meningitis in Vietnamese Adults. Plos One. 2008:3(3):1772-8

23. World Health Organization. Communicable Diseases Cluster, Stop TB Department. Towards universal access to diagnosis and treatment of multidrug-resistant and extensively drug-resistant tuberculosis by 2015 
WHO progress report 2011. Geneva, Switzerland: World Health Organization; 2011 [cited 2015 Jun 16]. Available from: http://whqlibdoc.who.int/ publications/2011/9789241501330_eng.pdf. Accessed 15 Nov 2015.

24. Ely EW, Inouye SK, Bernard GR, Gordon S, Francis J, May L, Truman B, Speroff T, Gautam S, Margolin R, Hart RP, Dittus R. Delirium in mechanically ventilated patients: validity and reliability of the confusion assessment method for the intensive care unit (CAM-ICU). JAMA. 2001;286(21):2703-10

25. Afessa B. Clinical Course, Prognostic Factors, and Outcome Prediction for HIV Patients in the ICU *: The PIP (Pulmonary Complications, ICU Support, and Prognostic Factors in Hospitalized Patients With HIV) Study. CHEST J. 2000;118(1):138

26. Dickson SJ, Batson S, Copas AJ, Edwards SG, Singer M, Miller RF. Survival of HIV/AIDS patients in the intensive care unit in the era of highly active antiretroviral therapy. Thorax. 2007;62(11):964-8.

27. Narasimhan M, Posner AJ, De Palo VA, Mayo PH, Rosen MJ. Intensive Care in Patients With HIV Infection in the Era of Highly Active Antiretroviral Therapy. Chest. 2004;125(5):1800-4.

28. Barbier F, Coquet I, Legriel S, Pavie J, Darmon M, Mayaux J, et al. Etiologies and outcome of acute respiratory failure in HIV/AIDS patients. Intensive Care Med. 2009;35(10):1678-86.

29. Lockman S, Hone N, Kenyon TA, Mwasekaga M, Villauthapillai M, Creek T, et al. Etiology of pulmonary infections in predominantly HIV/AIDS adults with suspected tuberculosis, Botswana. Int J Tuberc Lung Dis. 2003;7(8):714-23.

30. Morris A, Masur H, Huang L. Current issues in critical care of the human immunodeficiency virus-infected patient. Crit Care Med. 2006;34(1):42-9.

31. Segal LN, Methe BA, Nolan A, Hoshino Y, Rom WN, Dawson R, et al. HIV-1 and Bacterial Pneumonia in the Era of Antiretroviral Therapy. Proc Am Thor Soc. 2011;8(3):282-7.

32. Wunderink RG, Niederman MS. Update in Respiratory Infections 2011. Am J Respir Crit Care Med. 2012;185(12):1261-5.

33. Pacheco AG, Durovni B, Cavalcante SC, Lauria LM, Moore RD, Moulton LH, et al. AIDS-Related Tuberculosis in Rio de Janeiro, Brazil. PLoS One. 2008;3(9):e3132.

34. Powell K. Survival for Patients With HIV Admitted to the ICU Continues to Improve in the Current Era of Combination Antiretroviral Therapy. CHEST. 2009;135(1):11-7.

35. Meybeck A, Lecomte L, Valette M, Van Grunderbeeck N, Boussekey N, Chiche A, et al. Should highly active antiretroviral therapy be prescribed in critically ill HIV/AIDS patients during the ICU stay? A retrospective cohort study. AIDS Res Ther. 2012;9(1):27.

36. Morris AM, Huang L, Bacchetti P, Turner J, Hopewell PC, Wallace JM, et al. Permanent declines in pulmonary function following pneumonia in human immunodeficiency virus-infected persons. The Pulmonary Complications of HIV Infection Study Group. Am J Respir Crit Care Med. 2000;162(2):612-6.

37. Croda J, Croda MG, Neves A, De Sousa dos Santos S. Benefit of antiretroviral therapy on survival of human immunodeficiency virus-infected patients admitted to an intensive care unit. Crit Care Med. 2009;37(5):1605-11.

38. Corona A, Raimondi F. Caring for HIV/AIDS patients in the ICU in the highly active antiretroviral therapy era. Curr HIV Res. 2009;7(6):569-79.

39. Chiang $\mathrm{H}-\mathrm{H}$, Hung $\mathrm{C}-\mathrm{C}$, Lee $\mathrm{C}-\mathrm{M}$, Chen $\mathrm{H}-\mathrm{Y}$, Chen $\mathrm{M}-\mathrm{Y}$, Sheng $\mathrm{W}-\mathrm{H}$, et al. Admissions to intensive care unit of HIV/AIDS patients in the era of highly active antiretroviral therapy: etiology and prognostic factors. Crit Care. 2011;15(4):R202.

40. Orsini J, Ahmad N, Butala A, Flores R, Tran T, Llosa A, et al. Etiology and Outcome of Patients with HIV Infection and Respiratory Failure Admitted to the Intensive Care Unit. Int perspect infect dis. 2013;2013:732421.

41. Balkema CA, Irusen EM, Taljaard JJ, Koegelenberg CF. Tuberculosis in the intensive care unit: a prospective observational study. Int J Tuberc Lung Dis. 2014;18(7):824-30

42. Nickas G, Wachter RM. Outcomes of intensive care for patients with human immunodeficiency virus infection. Arch Intern Med. 2000;160(4):541-7.

43. Bray S, Gedeon J, Hadi A, Kotb A, Rahman T, Sarwar E, Savelyeva A, Sévigny M, Bakanda C, Birungi J, Chan K, Yaya S, Deonandan R, Mills EJ. Predictive value of CD4 cell count nadir on long-term mortality in HIV-positive patients in Uganda. HIV AIDS (Auckl). 2012;4:135-40.

44. Miller $\mathrm{V}$, Mocroft A, Reiss $P$, Katlama C, Papadopoulos Al, Katzenstein $T$, van Lunzen J, Antunes F, Phillips AN, Lundgren JD. Relations among CD4 lymphocyte count nadir, antiretroviral therapy, and HIV-1 disease progression: results from the EuroSIDA study. Ann Intern Med. 1999:130(7):570-7.

45. Kogmar S, Schön T, Balcha TT, Jemal ZH, Tibesso G, Björk J, Björkman P. CD4 cell levels during treatment for tuberculosis (TB) in Ethiopian adults and clinical markers associated with CD4 lymphocytopenia. PLoS One. 2013;8(12):e83270.

46. Cardoso SW, Grinsztejn B, Velasque L, Veloso VG, Luz PM, Friedman RK, Morgado M, Ribeiro SR, Moreira RI, Keruly J, Moore RD. Incidence of modifying or discontinuing first HAART regimen and its determinants in a cohort of HIV-infected patients from Rio de Janeiro, Brazil. AIDS Res Hum Retroviruses. 2010;26(8):865-74.

47. Waddell RD, Lishimpi K, von Reyn CF, Chintu C, Baboo KS, Kreiswirth B, et al. Bacteremia due to Mycobacterium tuberculosis or M. bovis, Bacille CalmetteGuerin (BCG) among HIV-positive children and adults in Zambia. AIDS. 2001;15(1):55-60

48. Amancio RT, Japiassu AM, Gomes RN, Mesquita EC, Assis EF, Medeiros DM, et al. The innate immune response in HIV/AIDS septic shock patients: a comparative study. PLoS One. 2013;8(7):e68730.

49. Crump JA, Ramadhani HO, Morrissey AB, Saganda W, Mwako MS, Yang LY, et al. Bacteremic disseminated tuberculosis in sub-saharan Africa: a prospective cohort study. Clin Infect Dis. 2012;55(2):242-50.

50. Burman W, Weis S, Vernon A, Khan A, Benator D, Jones B, Silva C, King B, LaHart $C$, Mangura $B$ et al. Frequency, severity and duration of immune reconstitution events in HIV-related tuberculosis. Int J Tuberc Lung Dis. 2007;11:1282-9.

51. Holland DP, Hamilton CD, Weintrob AC, Engemann JJ, Fortenberry ER, Peloquin CA, et al. Therapeutic drug monitoring of antimycobacterial drugs in patients with both tuberculosis and advanced human immunodeficiency virus infection. Pharmacotherapy. 2009;29(5):503-10.

52. Zahar J-R, Azoulay E, Klement E, De Lassence A, Lucet J-C, Regnier B, et al. Delayed treatment contributes to mortality in ICU patients with severe active pulmonary tuberculosis and acute respiratory failure. Intensive Care Med. 2001;27(3):513-20.

53. Wilkinson KA, Meintjes G, Seldon R, Goliath R, Wilkinson RJ. Immunological characterisation of an unmasking TB-IRIS case. S Afric Med J. 2012;102(6):512-7.

54. Kim YJ, Pack KM, Jeong E, Na JO, Oh Y-M, Lee SD, et al. Pulmonary tuberculosis with acute respiratory failure. Eur Resp J. 2008;32(6):1625-30.

55. Nicolls DJ, King M, Holland D, Bala J, del Rio C. Intracranial tuberculomas developing while on therapy for pulmonary tuberculosis. Lancet Infect Dis. 2005;5(12):795-801.

56. Thwaites GE, van Toorn R, Schoeman J. Tuberculous meningitis: more questions, still too few answers. Lancet Neurol. 2013;12(10):999-1010.

57. Sonneville R, Ferrand H, Tubach F, Roy C, Bouadma L, Klein IF, et al. Neurological complications of HIV infection in critically ill patients: Clinical features and outcomes. J Infection. 2011:62(4):301-8.

58. Casalino E, Mendoza-Sassi G, Wolff M, Bedos JP, Gaudebout C, Regnier B, Vachon F. Predictors of short- and long-term survival in HIV-infected patients admitted to the ICU. Chest. 1998;113(2):421-9.

\section{Submit your next manuscript to BioMed Central and we will help you at every step:}

- We accept pre-submission inquiries

- Our selector tool helps you to find the most relevant journal

- We provide round the clock customer support

- Convenient online submission

- Thorough peer review

- Inclusion in PubMed and all major indexing services

- Maximum visibility for your research

Submit your manuscript at www.biomedcentral.com/submit
) Biomed Central 